\title{
Review on Quality Management Model based on Process Approach
}

\author{
Hongfei Guo \\ Institute of Physical Internet, Jinan University University \\ Zhuhai, 519070, China \\ E-mail: ghf-2005@163.com
}

$\mathrm{Ru}$ Zhang (Corresponding author)

Finance Department of International Bussiness School, Jinan University

Zhuhai, 519070, China

E-mail: zhangru@stu2016.jnu.edu.cn

Min Zou

School of Translation Studies, Jinan University

Zhuhai, 519070, China

E-mail: airelmin1219@qq.com

Junda Yang
Finance Department of International Bussiness School, Jinan University
Zhuhai, 519070, China
E-mail: 13676097885@163.com

Jingge Zhang

School of Foreign Languages, Jinan University

Guangzhou, 510632, China

E-mail: jarvis_is_jingge@foxmail.com 
Zhihui He

Institute of Physical Internet, Jinan University University

Zhuhai, 519070, China

\author{
Ting Qu \\ Institute of Physical Internet, Jinan University University \\ Zhuhai, 519070, China
}

Congdong Li

Institute of Physical Internet, Jinan University University

Zhuhai, 519070, China

Guoquan Huang

Institute of Physical Internet, Jinan University University

Zhuhai, 519070, China

$\begin{array}{lc}\text { Received: September 7, } 2018 & \text { Accepted: September 28, } 2018 \quad \text { Published: Nov. 22, } 2018 \\ \text { doi:10.5296/bmh.v6i2.13955 } & \text { URL: http://dx.doi.org/10.5296/bmh.v6i2.13955 }\end{array}$

\begin{abstract}
As one of the core methods of the quality management system in the automotive industry, the process approach is an important tool for realizing the quality assurance of complex manufacturing systems with multi-sector, multi-process and multi-quality indicators. This paper first gives an overview of the quality management in the automotive industry, and then introduces the research status of the quality management system based on process approach in the industry, providing direction for the automotive industry in both research and practice of process-approach based quality management models.
\end{abstract}

Keywords: automotive industry, process approach, quality management system, PDAC cycle 


\section{Preface}

Since the development, improvement and implementation of the ISO9000 quality system certification and related standards, the world's quality management level has been upgraded. Regarding the quality management system, there are similarities and differences between industries. In other words, in the automotive industry, ISO9000 standard was unable to meet the special requirements of its quality management (2015). Therefore, the International Automotive Task Force (IATF) firstly issued ISO/TS16949 in 1999, and has been upgraded to ISO/TS16949:2002 and ISO/TS16949:2009. In addition, different automotive manufacturers (such as BMW, Chrysler, GM and Ford) still maintain their own management method in the supply chain management of quality management system. The process approach is considered as one of the core tools in quality management system of automotive industry and takes an important position in industrial application. In order to enhance the awareness for engineers and researchers on quality management model based on process approach, this paper gives a brief overview on the theory of quality management model based on process approach and technical research results.

\section{Overview of Quality Management System in Automotive Industry}

\subsection{History of ISO/TS16949}

International Automotive Task Force (IATF) was established in 1996, whose purpose is to coordinate the standards of automotive quality system among car manufacturer in the world so as to facilitate the integration and management of supplier of automotive OEM. The members of IATF consist of the Technical Committee on Quality Management and Quality Assurance, nine car factories and five national associations. The nine car plants are BMW Group, Daimler AG, Fiat Group Automotives, Chrysler LLC, PSA Peugeot Citroen, Renault, Ford Motor, Volkswagen AG and General Motors Corporation. The five national associations are ANFIA/Italy, FIEVA/France, SMMT/UK, VDA-QMC/Germany and AIAG/USA.

Based on ISO9001:1994 Quality System Standard, the IATF and ISO/TC176 Quality Assurance Committee integrated the German VDA, American QS-9000, French and German's quality management system standards. In 1999, they issued the first version of ISO/TS16949:1999 standard, and then issued the ISO:2000 edition. IATF combined the ISO:9001 edition with the ISO:2000 edition standard to formulate the technical specifications of ISO/TS16949:2002, whose main changes were the special requirements for the automotive industry. The International Organization for Standardization (ISO) issued ISO 9001:2008 standards in 2008 and the IATF issued ISO/TS16949:2009 edition in 2009. With the issue of quality management system standard of ISO 9001:2015 version, the IATF also issued IATF 16949 standards in 2016.

Major changes in the latest ISO 9001:2015 include requirements for safety-related components and processes, enhanced traceability requirements of product to support the latest regulatory changes, expanded requirements for products containing embedded software, requirements for warranty management processes including handling failures and using guidance for the automotive industry, clarifying the requirements of sub-supplier 
management and development and increasing the requirements of corporate responsibility.

The target of ISO / TS16949 is to establish a quality management system with continuous improvement, defect prevention, reduction of variation and waste in the automotive supply chain. The focus of the quality management system is to meet and constantly exceed expectation of customer, by full participation and effective incentives for staff and the constantly improved quality management system. By quick response system, problem solution and surveys of customer satisfaction, the effectiveness and efficiency of enterprise have been constantly improved.

TS16949 standard provides many effective and feasible control methods, and method with the most far-reaching impact should be the five tools focused by AIAG, including APQP (Advanced Product Quality Planning), MSA (Measurement System Analysis), SPC (Statistical Process Control) PPAP (Production Part Approval Process) and FMEA (Failure Mode Effect Analysis), TPM (Total Productive Maintenance).

ISO/TS16949 put forward the concept of product life cycle management, which requires organizations to control processes, such as identifying customer voices, design and development of product, development and selection of supplier, monitoring of manufacturing process, monitoring of product and planning of measurement, management, error prevention and substitution of nonconforming product.

ISO / TS16949 requires organizations to identify potential manufacturing risks in real process, and systematically analyze and evaluate the identified risks, so as to formulate appropriate measures to prevent the occurrence of nonconforming products.

The standard strongly put an emphasis that chief executives must plan and manage business plans, formulate strategies and targets for business development by short-term, medium-term and long-term business planning, formulate annual goals and relevant process indexes based on medium-term and long-term plans and organizational strategies, and identify weakness of groups by data analysis and makes improvement to constantly improve the organization's performance.

\subsection{Current Research of ISO/TS16949 Application}

Jin (2016), utilizing with development experience of new product in steel company, explained the value in the development of ultra-deep dip galvanized iron alloy product used for the vehicle in the quality management system of ISO/TS16949; Tian (2015) further explained about three supporting pillar basis for national quality foundation, which are measurement, standardization and qualification ratings, and also made analysis on the positioning, which helped to understand key points of design of quality at top level. Zhao (2014) briefly described the advantages and shortcomings of introducing ISO/TS16949 quality system into Anshan Iron and Steel Co by her own management experience. Li (2014) analyzed the recall risk of defective automotive products in recent years, $80 \%$ of which were due to the lack of original-part supply chain. Taking the supply chain of DPCA company as an example, she discussed the shortcomings of the current evaluation system and put forward her own management index. Dyer \& Chu derived different trust models from the supply chain relation 
between 453 supply chains in the United States, Japan and South Korea and their vehicle customers. They emphasized on the stability and cost of supply chain led by different trust. P.O. et al. (2013) discussed about the selection and evaluation model of supply chain based on ISO/TS16949 requirements. The model was established by using a method of VAHP (Voting Analysis Hierarchy Process) based on QFD. Zhang (2012) comprehensively introduced the ISO/TS16949 certification of SAIC General Motors Co. Ltd. and proposed the countermeasures upon the major problems such as insufficient operation validity of quality system, insufficient outsourcing quality of suppliers, insufficient monitoring validity of manufacturing process and insufficient effectiveness of quality assurance mechanism, which had reference significance for analyzing and improving the effective system design of quality management system. PoP and Elod (2015) discussed the value of ISO/TS16949 in preventing defects, reducing variation and waste, and enhancing continuous improvement. They combined with the certification of the quality management system of Romanian automotive supply chain, and shared the application and improvement of SPC in quality control. AIAG (2015), according to the survey of North American automotive supply chain enterprises, found that the five major problems faced by the supply chain were problem solving, customer special requirements management, quality management system effectiveness, product development and experience loss. He also carried out appropriate extension and proposed directional improvement approaches, which had great reference value for improving the quality management of supply chain.

\section{Process and Process Approach of Quality Management System}

\subsection{Process Approach}

Ao Jing (2016) defined Process Approach as process management methods or process management. ISO9000 standardized the process management, and named it "process approach" in 2000. In the understanding and operation of QMS (Quality Management System ) was systematically identification and management of the organization's application processes. It was also elaborated specifically in "Any activity or group of activities that use resources to turn input into output can be thought of as a process. For an organization to function effectively, many interrelated and interacting processes must be identified and managed. In general, the output of one process will directly become the input of the next process. Systematically identifying and managing the processes of organization's application, especially the interaction among the processes, is called 'process approach'." Process approach regarded customers as their management focus and it was guided by the customer demands. The organizations' processes were generally divided into three categories: COP (Customer Oriented Process), MP (Management Process) and SP (Support Process). Xie Jianhua (2012) explained the three kinds of processes separately: COP is any process linked directly to organizations and customer interfaces. The inputs come directly from customers and the outputs go directly to customers, or to the process of increasing customers' satisfaction level, such as product quoting, product designing, order processing, product manufacturing, customer feedback processing, etc. SP was a process supporting the operation of COP, examples of which included personnel training, facility management, purchasing management, metering device management, document and records management, etc. SP 
generally linked to COP and MP. The processes managed organizations or their QMS, such as business planning process, internal audit process, management process, continuous improvement process, etc. The three types of processes associated with each other and constituted the process management system.

\subsection{PDAC Cycle}

Recurring PDAC cycles can help organizations or businesses fully identify risks in quality management to better maintain and operate quality management systems. The source of PDAC is PDS, namely Plan, Do, See, which was proposed by Walter A. Shewart, the father of Statistical Quality Control (SQC) in the United States. American statistician Dr. Deming (W. E. Deming) deeply excavated it and applied it to the process of product quality management, forming a unique scientific management system PDAC cycle.

The PDAC cycle is the primary tool for process methods. The PDAC cycle includes: Plan is to establish the goals and processes of the system according to the customer's requirements and organizational guidelines, determine the resources needed to achieve the results, and identify and respond to risks and opportunities; implementation (Do) refers to implementation Planning: Checking refers to monitoring and measuring processes and products and services based on policies, objectives, requirements, and planned activities, and reporting results: Disposal (ACT) means when necessary, steps are taken to improve performance. Successful experience should be affirmed, standardized, or made into work instructions, so that employees can follow in the future work, and the lessons of failure should be summarized and give improvement methods to avoid recurrence.

Many scholars made a lot of research in the use of process approach to achieve quality management optimization. Xu et al. (2018) improved and implemented turtle diagram in process approach according to VDA standards in order to realize the identification, evaluation and management of process risks. They could thus continuously improve the risk identification method and quality control level by PDAC circulation; Yan (2018) proposed a group quality management model for the automotive companies, and conducted research and design on seven aspects: management operation system, sales operation system, R\&D operation system, quality operation system, manufacturing operation system, procurement operation system and human resource operation system. He then proposed corresponding project implementation safeguards; Yao (2017) used quality management tools to improve the quality of new energy vehicle development projects, and the process control approach is the core method to achieve results; Shi (2017) summarized the problems in the design and implementation of quality management system in China's manufacturing industry: low attention of high-level corporate on product quality; lack of the concept of quality management priority in corporate culture; serious corporate formalism; management methods, etc. And he made some suggestions; Shi et al. (2015) summarized the intrinsic relationship and inheritance characteristics of the existing major quality management systems in the automotive industry, discussed the differences between VDA6.1 together with ISO/TS16949 standards and ISO9000, and proposed to strengthen the application of process approach based on the special practical experience of the automotive industry; Xie (2005) proposed the 
management model of "customer-process-performance" of process method based on the process approach in ISO9000 family and personal consulting experience; Guo (2015) used a company as an analysis case to comprehensively use the turtle map analysis method, APQP method and PFMEA method to realize process-based quality control.

\section{Conclusion}

In the manufacturing process of automotive industry, the quality management determines the quality of the final product. In automotive manufacturing system with multi-sector, multi-process and multi-quality indicator, the QMS based on process approach has excellent effect in application. Yet theoretically, the QMS based on process approach is relatively scarce, and there are few studies targeting at QMS of sub-sectors of the automotive industry, which in the future should be one of the research direction of QMS based on process approach.

\section{References}

AIAG. (2015).Quality 2020, 2015.

Ao, J. (2016). Process Approach. Standards Press of China.

Casadesús, M. (2015). Exploring the service management standard iso 20000. Total Quality Management \& Business Excellence, 26(5-6), 515-533. https://doi.org/10.1080/14783363.2013.856544

Chu, J. H. D. W. (2000). The determinants of trust in supplier-automaker relationships in the U.S., Japan and Korea. Journal of International Business Studies, 31(2), 259-285. https://doi.org/10.1057/jibs.2010.34

Dilek, P. O., Asli, A., \& Nursel, O. (2013). A Supplier Evaluation System for Automotive Industry According to ISO/TS16949 Requirements. International Journal of Engineering Research and Applications, 3, 2356-2362. https://doi.org/10.1.1.377.7348

Guo, Y. P. (2015). ISO/TS16949Applied on ISO/TS16949 Quality Management System in JT company. Doctoral dissertation, Hebei University of Science \& Technology.

Jin, Y. G., Zhou, H. W., Fu, D. H., Li, S. Y., \& Wang, K. P. (2016). Application of ISO/TS 16949 Quality Management System on SEDDQ Hot Dip Galvannealed Automobile Steel during Development. Metal World, (2), 71-75.

KAIDA Consultants. (2003). ISO9001:2000Uderstanding and Operation of quality Management system/understanding and implementation of training Series. China Electric Power Press.

Li, R., \& Meng, Q. X. (2014). Quality Ability Promotion Method Analysis for Auto Parts Enterprises_taking DP company for example. Automobile Parts, (3), 56-58. https://doi.org/10.19466/j.cnki.1674-1986.2014.03.014

Pop, L. D., \& Elod, N. (2015). Improving product quality by implementing ISO / TS 16949. Procedia Technology, 19(4), 1004-1011. https://doi.org/10.1016/j.protcy.2015.02.143 
Shi, N., Chen, K., \& Gao, R. G. (2015). Development and Research of General quality Management system in Automobile Industry. Auto Industry Research, (2), 39-42.

Shi, X. (2017). Design and Implementation Research of Quality Management System of Automobile Construction Enterprises in China. Popular Standardization, (6), 52-55.

Tian, Z. Y., Shang, T. S., \& Su, F. (2015). On the orientation of Certification and Accreditation on National Quality Institute. China Certification \& Accreditation, (3), 32-34.

Xie, J. H. (2012). ISO/TS 16949 Quality Management System in automobile industry: 2009 New Implementation (Jianhua Xie ed.). China Economic Publishing House.

Xie, X. Z. (2005). The Study of the Process Approch and Its Application in the ISO9000 Family of Stangards. Doctoral dissertation, Southwest Jiaotong University.

Xu, D., Li, Q. J., Long, M. H., Yan, C. Q., \& Zhong, Z. Y. (2018). Research and Application of Risk Identification and Management Method basing on Process Approach. Internal Combustion Engines and Accessories. https://doi.org/10.19475/j.cnki.issn1674-957x.2018.11.077

Yan, S. J. (2018). Study on Construction of Quality Management System of SL Group Company. Tianjin Polytechnic University.

Yao, P. L. (2017). Quality Management in the process of developing New Energy vehicles. Auto Time, (18), 54-57.

Yu, Q. H. (2017). New quality Management Standard for Automobile industry IATF16949: officially issued in 2006. Automobile Parts, (1), 46-46.

Zhang, L. (2012). In ISO/TS16949 standard SGM company quality management problem research. Doctoral dissertation, Liaoning University.

Zhao, H. Y. (2014). ISO/TS16949 Research on Standard implement Strategy. Doctoral dissertation, Jilin University.

\section{Copyrights}

Copyright for this article is retained by the author(s), with first publication rights granted to the journal.

This is an open-access article distributed under the terms and conditions of the Creative Commons Attribution license (http://creativecommons.org/licenses/by/4.0/). 